\title{
RELIABILITY AVAILABILITY FAILURE RATE OF VARIOUS GIRD CONNECTED PV SYTEM RENEWABLE ENERGY RESOURCES
}

\author{
DR. K. UMA MAHESWARI ${ }^{1}$, K. SUBRAHMANYAM ${ }^{2} \boldsymbol{*}$ DR. R. VIJAYA LAKSHMI ${ }^{3}$ \\ ${ }^{1}$ Associate professor, Dept of Humanities and Sciences, \\ ${ }^{2}$ Dept of Mechanical Engineering, \\ ${ }^{3}$ Associate professor, Dept of Humanities and Sciences \\ ${ }^{I}$ Srinivasa Ramanujan Institute of Technology, \\ ${ }^{2}$ JNTUA College of Engineering, \\ ${ }^{3}$ Srinivasa Ramanujan Institute of Technology, Anantapur, Andhra Pradesh India
}

\begin{abstract}
Recently renewable resources are like solar energy; wind energy generation take place all over world. The reliability, availability of the system having some complex failure rate and repair rate in the electric generation or power generation, based on PV system is pass the signal to transformer line and it is connected to grid via to household can be calculated. The System effects, modelling type among component resistances, coefficients of variations of load and resistances The focus of these papers is primarily on how the collective structure of the specific pieces impacts the subsequent reliability., series, parallel, combination of both arrangements, complex system, failure rate, repair rate, The mean time to failure, the mean time between failures, and the mean time recovery rate. The possibility of increasing reliability through redundancy is explained, as is the allocation of reliability to individual elements. Recognize the system arrival of digital technologies and the incorporation of renewable energy into energy systems in future studies. It will also keep operators updated on the status of the system's different nodes.
\end{abstract}

KEYWORDS: Reliability, Failure rate, Repair rate, Weibull distribution, Rayleigh distributions.

Received: Mar 18, 2021; Accepted: May 08, 2021; Published: May 12, 2021; Paper Id.: IJMPERDJUN202131

\section{INTRODUCTION}

Power system reliability, in general, addresses issues such as Service disruption and power outage It is delineated across several cases as an objective to try in terms of indices directly customer related. Studying the dependability of machine repair problems is critical in our lives because they are widely used in industrial and manufacturing systems. Any system can become unreliable for a variety of reasons. In traditional systems, the system's units have only two states: up and down. Many mathematical concepts, particularly those from probability and statistics, apply to reliability engineering. Many arithmetical distributions, including the Gauss (regular) distribution, the file distribution, the Rayleigh distribution, the exponential function, the Probability distributions, and a slew of others, can be used for a range of functions. Many objects are made up of multiple parts or elements. An element is any component or object that is considered in the investigated case as a whole and is not decomposed into simpler objects from the standpoint of reliability. We evolve analytical expression for the accessibility function, reliability function, and mean probability of failure using Differential equations techniques, and afterwards we execute a parametric inquiry that presents results obtained to examine the effects of various system parameters on system 
reliability requirements.

\section{METHODOLOGY}

\subsection{Reliability}

Reliability refers to the likelihood that a system will execute properly over a set timeframe. There is no requirement for, or productivity of, repair.

- The system adheres to the performance specifications as specified.

- Reliability implements a logarithmic failure law, that also means it decreases as the period considered for reliability calculations grows longer. In other phrases, the reliability of a system will be large at first, then gradually decline to its lowest severity over time. Reliability $(\mathrm{R}(\mathrm{t}))=\begin{gathered}-\lambda t \\ e\end{gathered}$

\subsection{Availability}

The possibility that a framework will perform correctly at a given point in time is alluded to as accessibility (not duration). Distractions can occur earlier or after the time case used to calculate the availability of the system.

- $\quad$ Be functional.

- At a time of use, it must meet the defined specifications.

- $\quad$ The steady-state availability is measured, considering potential downtime incidents.

$$
\text { Availability } \mathrm{A}(\mathrm{t})=\frac{M T B T}{M T B F+M T T R}
$$

\subsection{Failure Rate}

The number of times a component fails in one unit of time. calculate the measurements listed further down in this post. Failure pattern is determined in reliability geotechnical design as predicted failure frequency assuming the element is fully operational in its original conditions.

$$
\text { Formula: }(\lambda)=\frac{1}{M T B F}=\frac{1}{M T T F}
$$

\subsection{Repair Rate}

Each number of successful restoration operations on a failed system performed from each unit of time, calculate the measurements listed further down in this post.

$$
\mu=\frac{1}{M T T R}
$$

\subsection{Mean Time to Failure:}

The typical time required for a semi system component to are unable.

$$
\text { M TT F=total hrs of } \frac{\text { operation }}{\text { total no of units }}=1 / \lambda
$$

\subsection{Mean Time between Failure}

The average time among due to shortage of a replaceable system component. 
M T B F $=$ Total hrs. of operation/Total no of failures $=1 / \lambda$

\subsection{Mean Time Recovery}

The actual duration required to repair a defective part and bring it back into service. This ratio determines the time spent as during alert and diagnosis and treatment processes prior to the start of person who utilizes.

MTTR=Total hrs. of maintenance/Total no of repairs $=1 / \mu$

\subsection{Mean Time Detection}

The avg measure of years that elapsed here between incidence and detection of a malfunctions.

MTTD=Total hrs. of incidents Detection/Total no of Incidents

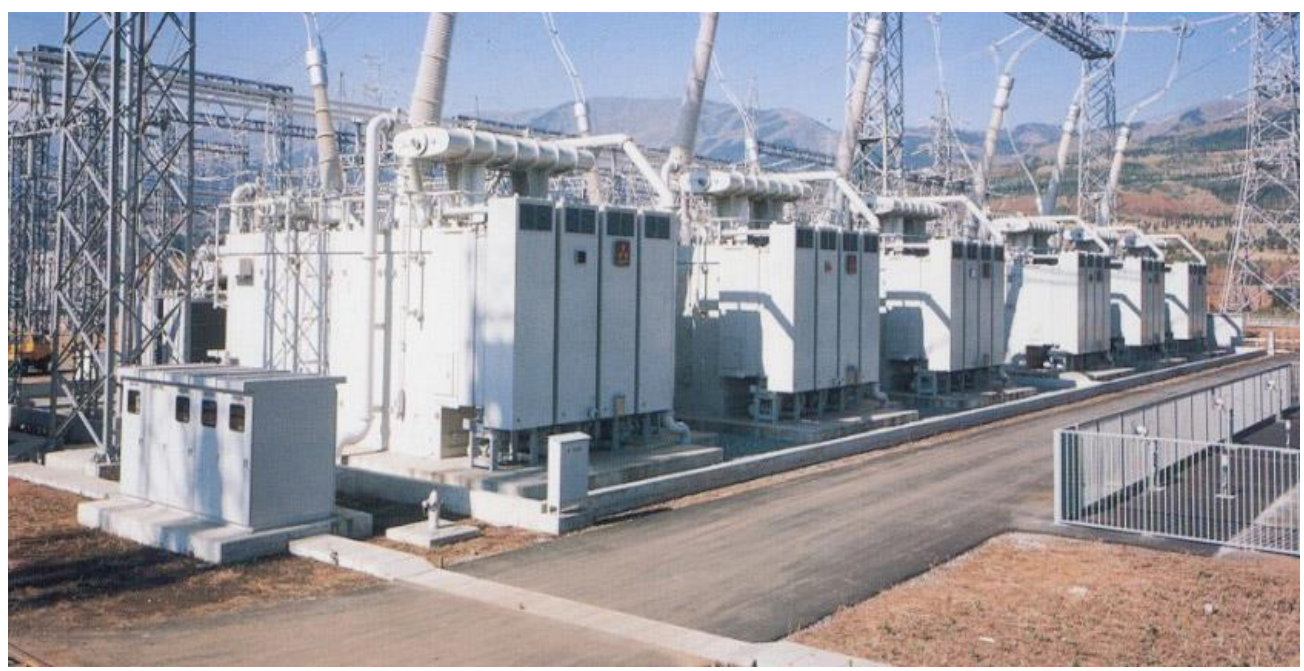

Figure 1: Series and Parallel Connections of Transformer Line to the grid.

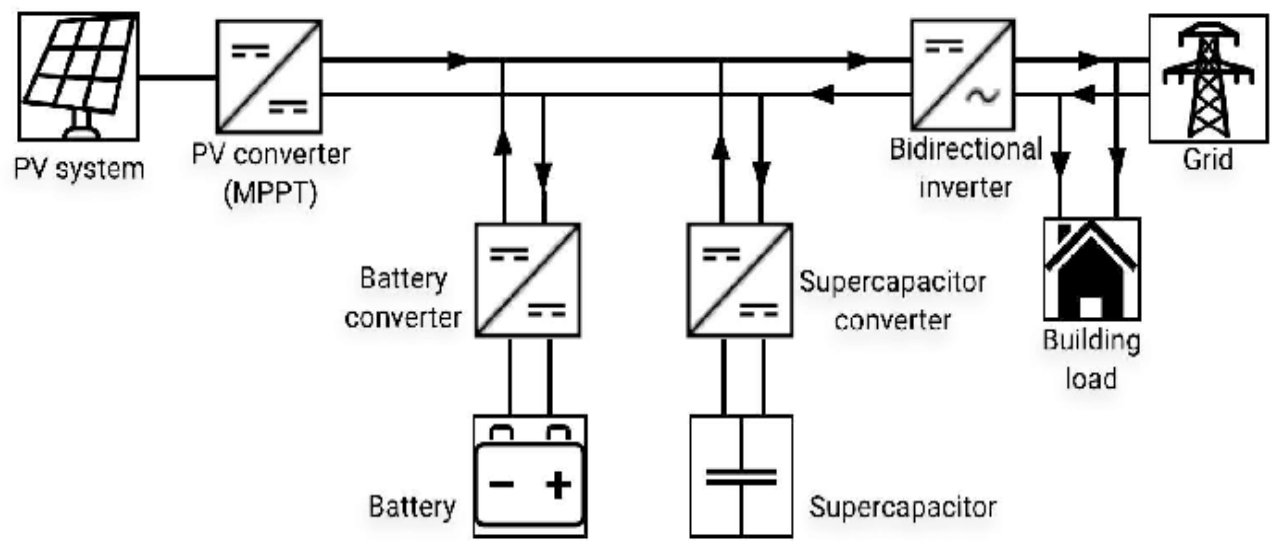

Figure 2: Circuit Connection from Gird to Household

The above transformers connections which having series, parallel and mixed connections which having various loads up and down as per time concern and season, based on that the gird has serval failure rate and recovery rate as per availability of current supply to the households. 


\section{VARIOUS COMPONENT SYSTEMS}

\subsection{Series Component System}

Input

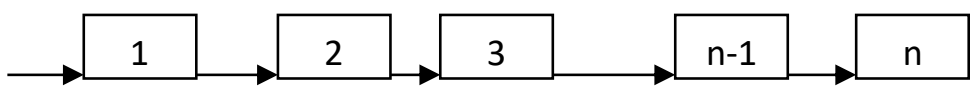

Out put

The above series component system made up of ' $n$ ' component system. It consists of following factors.

(1) The efficient mission of a series system is composed of the system performing its primary goal.

(2) For the scheme to is unable, only one element must fail. Let S1 become the event in which the component efficiently performs its primary goal. $\mathrm{I}=1,2,3-\mathrm{n}$

If $\mathrm{S}$ denotes the series system's reliability, then from the interpretations of reliability as well as system $\quad \mathrm{S}=\mathrm{P}$ $\left(\mathrm{E}_{1} \cap \mathrm{E}_{2} \cap \mathrm{E}_{3}-----\cap \mathrm{E}_{\mathrm{n}}\right)$.

Even though reliability is a probability system, eh represents the intersection of events. It is made up of the following elements.

1) The efficient mission of a series system composed of the system performing its intended purpose.

2) For the system to fail, only one element must fail.

Let $\mathrm{Si}$ indicate the event in which the component efficiently performs its intended function. I, where $\mathrm{i}=1,2,3$ -

If ' $\mathrm{S}$ ' denotes the series system's reliability, and from the meanings of validity and series system. $\mathrm{S} \quad=\quad \mathrm{P}$ $\left(\mathrm{E}_{1} \cap \mathrm{E}_{2} \cap \mathrm{E}_{3} \cap-----\cap \mathrm{E}_{\mathrm{n}}\right.$

Because dependability is a possibility, eqh represents the interconnection of events. If the occurrences Ei ( $\mathrm{i}=1,2$, $-n)$ are not self - reliant, we apply probability distribution and get $\mathrm{P}(\mathrm{E} 1) \mathrm{P}(\mathrm{E} 2 / \mathrm{E} 1) \mathrm{P}(\mathrm{E} 3 / \mathrm{E} 1 \mathrm{E} 2)$ $\mathrm{P} / \mathrm{En} / \mathrm{E} 1 \mathrm{E} 2 \_$_ En-1) $\mathrm{S}=\mathrm{P}(\mathrm{E} 1) \mathrm{P}(\mathrm{E} 2 / \mathrm{E} 1) \mathrm{P}(\mathrm{E} 3 / \mathrm{E} 1 \mathrm{E} 2)$ Where E1E2 = E1E2, E1E2E3 = E1E2E3, and so on.

Ei $(\mathrm{i}=1,2, \ldots \mathrm{n})$ are self-contained, as is the $\mathrm{n}$ we are interested in.

$$
\mathrm{R}=\mathrm{P}\left(\mathrm{E}_{1}\right) \mathrm{P}\left(\mathrm{E}_{2}\right) \mathrm{P}\left(\mathrm{E}_{3}\right)-----\mathrm{P}\left(\mathrm{E}_{\mathrm{n}}\right) \quad\left(\begin{array}{c}
\therefore \mathrm{P}\left[\frac{\mathrm{Ei}}{\mathrm{Ej}}\right]=\mathrm{P}[\mathrm{Ei}] \text { if events } \\
\text { Ei \& Ej are independent, etc }
\end{array}\right)
$$

(or)

$\mathrm{R}=\prod_{i=1}^{n} \mathrm{R}_{\mathrm{i}}$, for a mission of operation per unit time.

Where $\left.\mathrm{R}_{\mathrm{i}}=\mathrm{P}\right) \mathrm{Ei}$ )

Reliability of the series system, the mission of $600 \mathrm{hrs,} \mathrm{where} \mathrm{the} \mathrm{given} \mathrm{reliabilities} \mathrm{of} \mathrm{the} \mathrm{components} \mathrm{are} \mathrm{for} 600 \mathrm{hrs}$,

Single component

Input

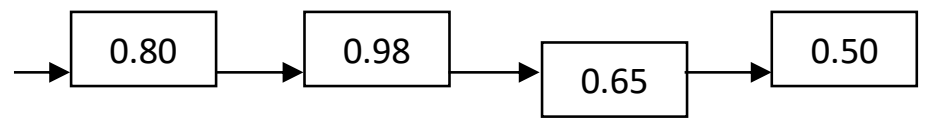

Out put

$R=R_{1} X R_{2} X R_{3} R_{4}$----- $R_{n}$ for mission $600 \mathrm{hrs}=0.80 X 0.98 X 0.65 X 0.50 \Rightarrow 0.2548$ 
Table 3.1.: Three Component System for Series

\begin{tabular}{|c|c|c|c|c|c|}
\hline S. No & $\begin{array}{c}\text { Reliability of the First } \\
\text { Component } \mathbf{0 . 8}\end{array}$ & $\begin{array}{c}\text { Second } \\
\text { Component } \\
\mathbf{0 . 9 8}\end{array}$ & $\begin{array}{c}\text { third } \\
\text { Component } \\
\mathbf{0 . 6 5}\end{array}$ & $\begin{array}{c}\text { Reliability of } \\
\text { given } \\
\text { Components } \\
\text { Systems }\end{array}$ & $\begin{array}{c}\text { Per of the total } \\
\text { System }\end{array}$ \\
\hline 1 & 0.8 & 0.98 & 0.65 & 0.224 & 25 \\
\hline 2 & 0.7 & 0.68 & 0.55 & 0.280 & 14 \\
\hline 3 & 0.4 & 0.80 & 0.9 & 0.256 & 12 \\
\hline 4 & 0.6 & 0.70 & 0.8 & 0.252 & 11 \\
\hline
\end{tabular}

Series Mean time failure rate (MTFT): MTTF $=\int_{0}^{\infty} R(t) d t$

$\mathrm{MTTF}=1 / \lambda 1$

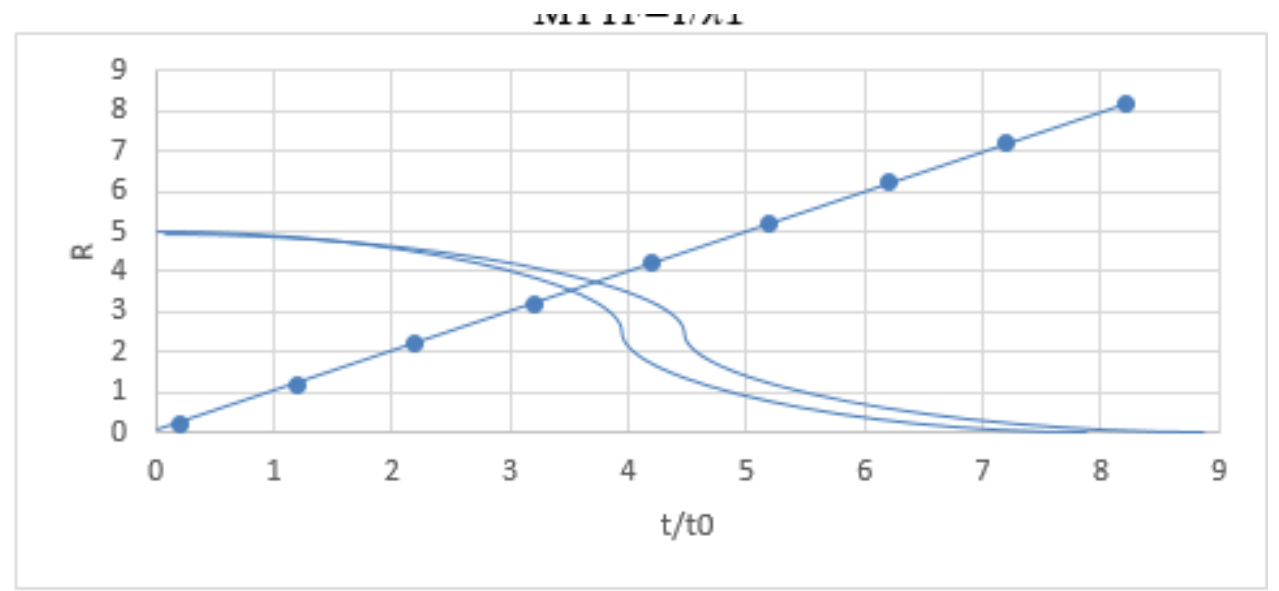

Figure 3.2.1: Mean Time Failure Rate of Reliability

\subsection{Reliability of a Parallel System}

The parallel system consists of

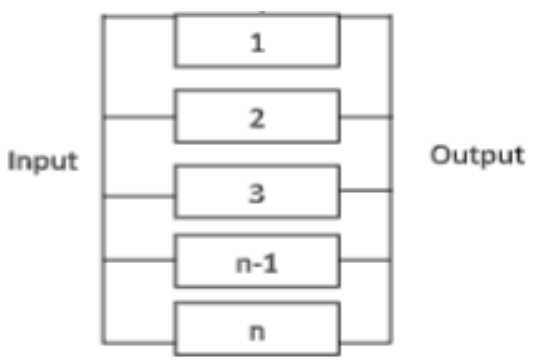

1.One element must function properly for the provided system to operate, and all other components must fail.

2.Let (-1) E 1 be the incident in which the element effectively needs to perform its intended of feature to the event Eid. Let (-1) S I be the component of reliability I where $\mathrm{I}=1,2,3-{ }_{-}$n for a mission of (-1)t time units. As a result, parallel parallel system is $\mathrm{R}=\mathrm{P}\left(\mathrm{E}_{1} \cup \mathrm{E}_{2} \cup \mathrm{E}_{3} \mathrm{U}---\mathrm{UE}_{\mathrm{n}}\right)$

$\mathrm{P}(\mathrm{A})+\mathrm{P}\left({ }_{A}^{-}\right)=1$, there $\mathrm{A}=\mathrm{E}_{1} \mathrm{UE}_{2} \mathrm{UE}_{3} \mathrm{U}----\mathrm{E}_{\mathrm{n}}$

$\mathrm{R}=\mathrm{I}-\mathrm{P}\left(\overline{E_{1} \cup E_{2} \cup E_{3} \cup---\cup E_{n}}\right)$ 
By using De-Morgan's law, we get at last

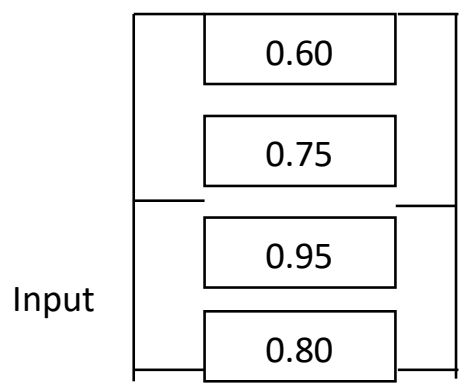

$$
\begin{aligned}
\mathrm{R} & =\mathrm{I}-\left(\mathrm{I}-\mathrm{R}_{1}\right)\left(1-\mathrm{R}_{2}\right)\left(1-\mathrm{R}_{3}\right)----\left(1-\mathrm{R}_{\mathrm{n}}\right) \\
\mathrm{R} & =\mathrm{I}-\underset{\pi}{n} \operatorname{n}\left(\mathrm{I}-\mathrm{R}_{\mathrm{i}}\right) \text { for }_{n}^{-1} \text { mission } \\
\text { Output } \quad \mathrm{R} & =\mathrm{I}-\left(\mathrm{I}-\mathrm{R}_{1}\right)\left(\mathrm{I}-\mathrm{R}_{2}\right)\left(\mathrm{I}-\mathrm{R}_{3}\right)----\left(\mathrm{I}-\mathrm{R}_{\mathrm{n}}\right) \\
\mathrm{R} & =\mathrm{I}-(1-0.60)(\mathrm{I}-0.75)(\mathrm{I}-0.95)(\mathrm{I}-0.80) \\
& =0.999--- \text { for mission of } 90 \text { day }
\end{aligned}
$$

\section{Reliability of Both Series and Parallel System}
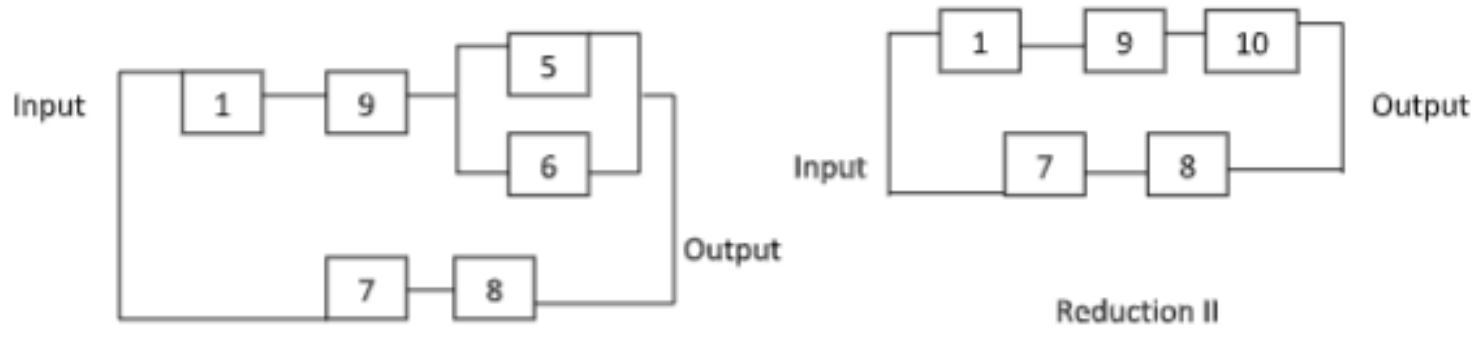

Reduction I

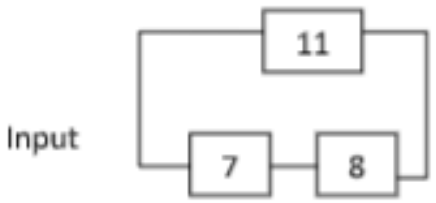

Reduction III

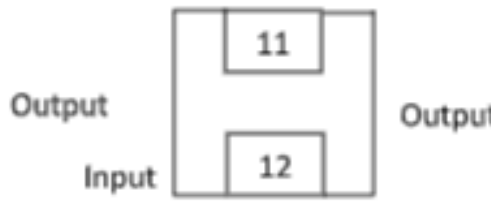

Reduction IV

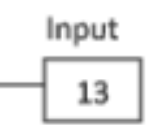

Output

Reduction V

Where $R_{1}=0.80, R_{2}=0.75, R_{3}=0.50, R_{4}=0.65, R_{s}=0.76, R_{s}=0.60, R_{7}=0.95, R_{s}=0.90$.

Input

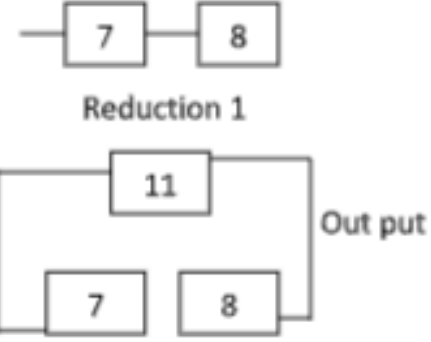

Reduction III

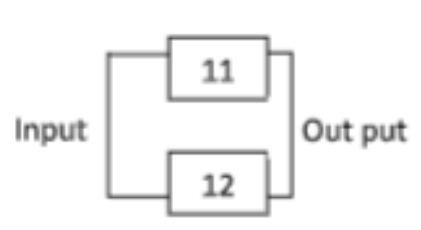

Reduction IV
Input

13

Out put

Where $R_{s}=0.80, R_{2}=0.75, R_{a}=0.50 . R_{a}=0.65 . R_{s}=0.76 R_{c}=0.60 . R_{3}=0.95 . R_{a}=0.90$

$\mathrm{R}_{9}=1-\left(1-\mathrm{R}_{2}\right)\left(1-\mathrm{R}_{3}\right)\left(1=\mathrm{R}_{4}\right)$

$$
\begin{aligned}
& =\mathrm{I}-(\mathrm{I}-0.75)(\mathrm{I}-0.50)(\mathrm{I}-0.65) \\
& =\mathrm{I}-0.0438=0.9562
\end{aligned}
$$




$$
\begin{aligned}
\mathrm{R}_{10} & =\mathrm{I}-\left(\mathrm{I}-\mathrm{R}_{5}\right)\left(\mathrm{I}-\mathrm{R}_{6}\right) \\
& =\mathrm{I}-(\mathrm{I}-0.76)(\mathrm{I}-0.60)=\mathrm{I}-0.96=0.904 \\
& =\mathrm{R}_{1} \mathrm{R}_{9} \mathrm{R}_{10}=0.80 \mathrm{X} 0.9562 \mathrm{X} 0.904=0.6915 \\
\mathrm{R}_{11} & \mathrm{R}_{7} \mathrm{R}_{8} \\
& =0.95 \times 0.90=0.855 \\
\mathrm{R}_{13} \quad \mathrm{I}-\left(\mathrm{I}-\mathrm{R}_{11}\right) & \left(\mathrm{I}-\mathrm{R}_{12}\right)=\mathrm{I}-0.085 \times 0.145 \\
= & 0.9553
\end{aligned}
$$

$\therefore$ Mixed system of reliability is $0.9553^{\prime}$

\subsection{Mean Time Failure Rate of Parallel System}

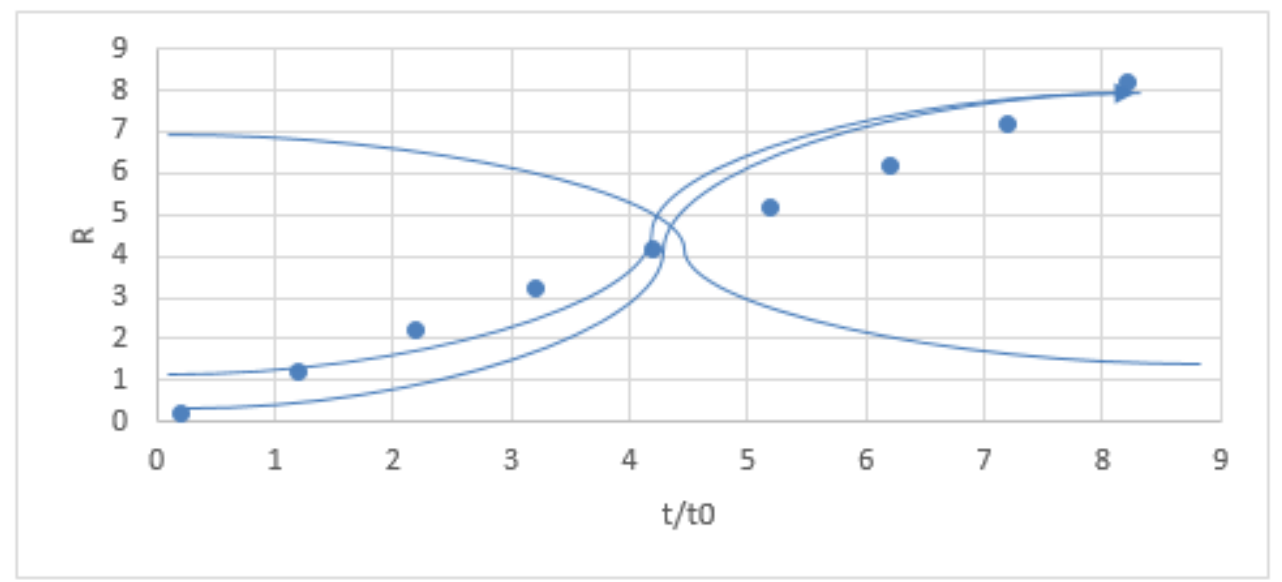

Figure 3.4.3.: MTTF of Parallel System

\subsection{Reliability (Analytical) Time - Dependent System}

Life Predictions Based on Analytical Data

Rupees $=\mathrm{R} 1 . \mathrm{R} 2 . \mathrm{R} 3$ for system reliability

The valves R1, R2, R3 were provided for a common time and the structural integrity was estimated for both the time, as system reliability is time - dependent.

$\mathrm{R}_{\mathrm{S}}(\mathrm{t})=\mathrm{R}_{1}(\mathrm{t}) \mathrm{R}_{2}(\mathrm{t}) \mathrm{R}=3_{(\mathrm{t})}$ According to Weibull life distribution of each component, the eq $\mathrm{q}^{\mathrm{h}}$ is $\mathrm{R}_{(\mathrm{t})}^{\mathrm{s}}=e^{-\left(t / n^{t n}\right)^{B_{1}}}$ $e^{-\left(t / n^{2}\right)^{B_{2}}} e^{-\left(t / n^{3}\right)^{B_{3}}}$

$$
\mathrm{R}_{\mathrm{s}}(\mathrm{t})=e^{-\left(t / n^{1}\right)^{B_{1}}} e^{-1 / 2^{t}}\left(I-\emptyset\left(\frac{t-43}{03}\right)\right)
$$

Assume that component as follows exponential distribution with mean of $10,000\left(\pi=10,000, \lambda=\frac{1}{10,000}\right) \&$ component 2 follows a Weibull distribution with $\mathrm{P}=6, \mathrm{n}=10,000$ The reliability equation 
$\mathrm{R}_{\mathrm{S}}(\mathrm{t})=\mathrm{R}_{1}(\mathrm{t}) \mathrm{R}_{2}(\mathrm{t})=e^{-\frac{1}{10,000}+} e^{-\left(\frac{\mathrm{t}}{10,000}\right)^{6}}$

System $F_{5}(t)=1-\left(\left(R_{i}(t) R_{2}(t)\right)\right.$

$$
=\mathrm{I}-\left(e^{-\lambda t} e^{-(t / n)^{B}}\right)=\mathrm{F}_{5}(\mathrm{t})=\frac{-d(R(t))}{d t}
$$

Probability density function

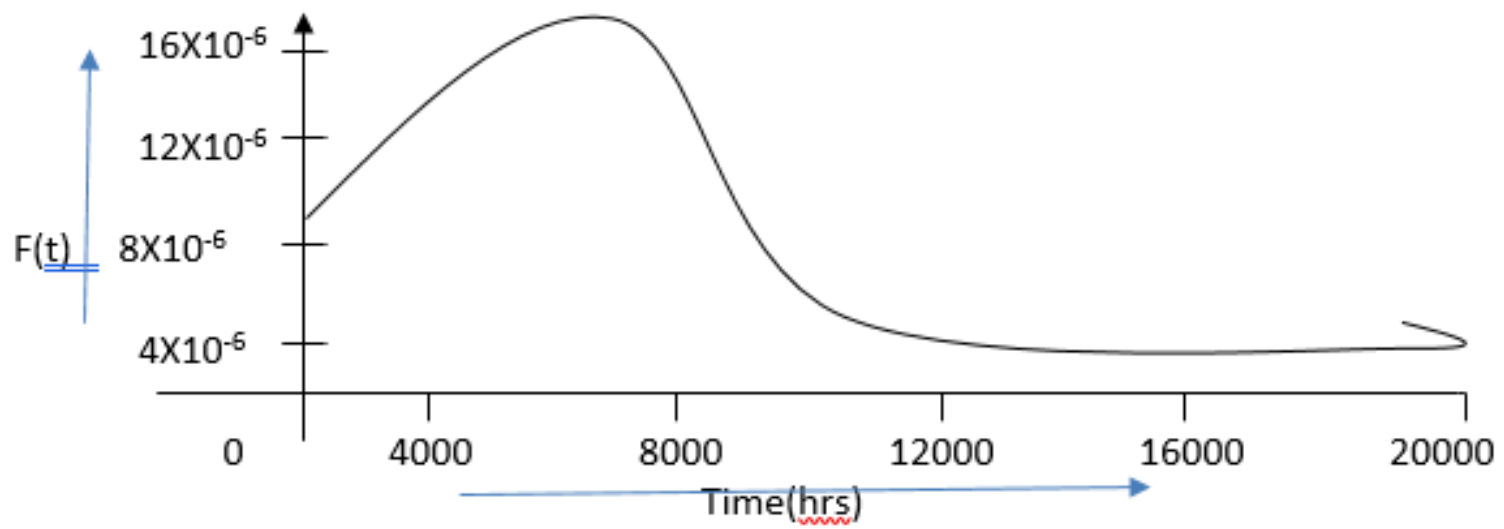

Figure 3: Failure Rate of System

\subsection{Conditional Reliability Failure System}

$$
\mathrm{R}(+/ 7)=\frac{R(T+t)}{R(T)} \mathrm{t}=1000 \mathrm{hr}, \mathrm{T}=500 \mathrm{hrs} .=0.9048
$$

System failure

$$
\lambda_{5}(t)=\frac{f_{5}(t)}{R_{5}(t)}
$$

For two component system

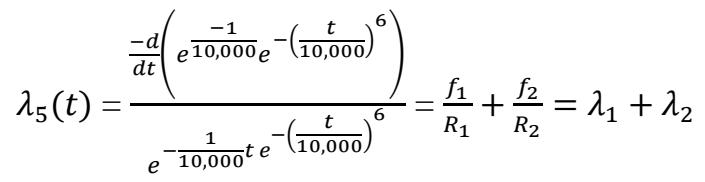




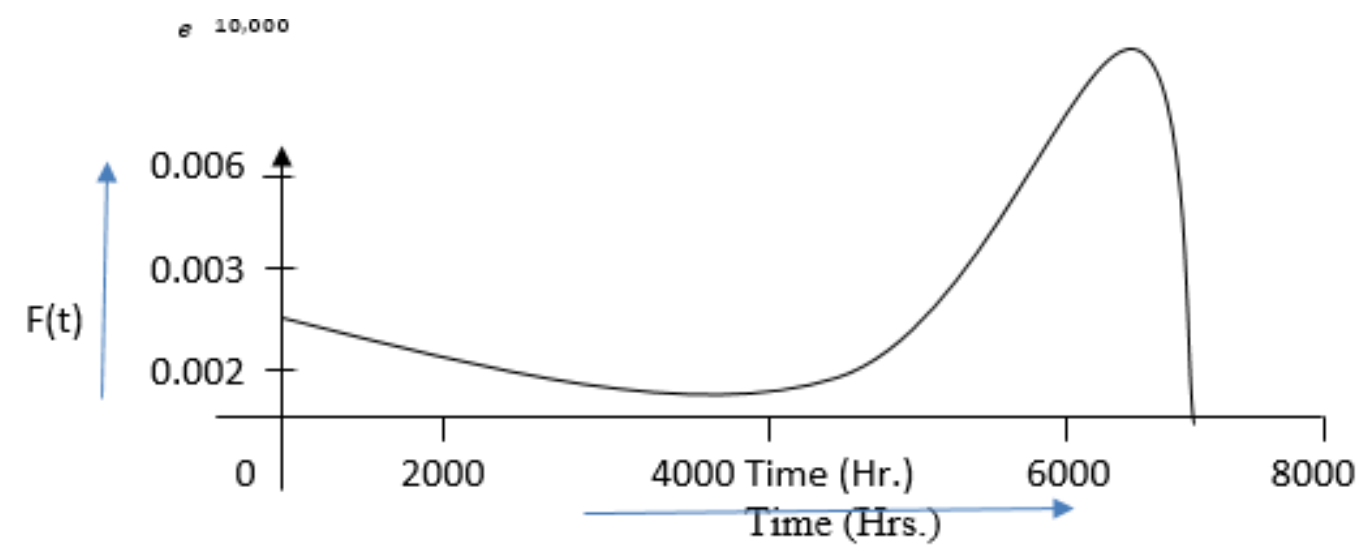

Figure 4: Failure Rate of complex System

\section{CONCLUSIONS}

In this paper, a numerical equation of rate of failure, availability, reliability, and mean time rate of failure for a repairable process of different Gird connected PV structure renewable energy was developed, probability density function, complex system, conditional mean failure system were obtained and the results as been shown in graph representation, mostly as of my failure rate less in complex type of PV system.

\section{REFERENCES}

1. Medhi.J. stochastic processes, New age international limited publishers New Delhi 2006.

2. Agrawal S.C manta s and shikha, IJRRA applied sciences 3(2),2010 1932-1999.

3. Weil, Attahiru,s.a \& yigiang, Journal of microelectronics reliability 1998.

4. El-Dames M.A Sharma mis reliability \& availability analysis of a repairable system JGokul journal 64(5),2014 7.5-83.

5. Srinath LS reliability Engineering East west press, New Delhi2013.

6. Bal Guruswamy E. reliability Engineering, Tata MacgrawHill, New Delhi.

7. Wai-ki-ching Michael k.ng, Markova chains algorithms applications NewDelhi-2008.

8. Dhillon B.s Reliability Engineering applications areas, Beta publishers, Gloucester ontariol992.

9. Johnson Barry 1988, Design \&analysis of fault tolerant digital systems.

10. Reni Nagarajan marline Anita a Chandrababu amurca models in system reliability with applications. 
